Review article

\title{
Intrapartum cardiotocograph monitoring and perinatal outcomes for women at risk: Literature review
}

\author{
Kirsten A. Small*, Mary Sidebotham, Jennifer Fenwick, Jenny Gamble \\ Transforming Maternity Care Collaborative, School of Nursing E' Midwifery, Griffith University, Australia
}

\section{A R T I C L E I N F O}

\section{Article history:}

Received 2 August 2019

Received in revised form 4 October 2019

Accepted 4 October 2019

Available online $\mathrm{xxx}$

\section{Keywords:}

Fetal monitoring

Perinatal mortality

Stillbirth

Cerebral palsy

Meta-analysis

\begin{abstract}
A B S T R A C T
Problem: Caesarean section rates have risen in high-income countries. One of the potential drivers for this is the widespread use of CTG monitoring.

Background: Intrapartum cardiotocograph monitoring is considered to be indicated for women at risk for poor perinatal outcome.

Aim: This systematic literature review with meta-analysis examined randomised controlled trials and non-experimental research to determine whether cardiotocograph monitoring rather than intermittent auscultation during labour was associated with changes in perinatal mortality or cerebral palsy rates for high-risk women.

Methods: A systematic search for research published up to 2019 was conducted using PubMed, CINAHL, Cochrane, and Web of Science databases. Non-experimental and randomised controlled trial research in populations of women at risk which compared intrapartum cardiotocography with intermittent auscultation and reported on stillbirth, neonatal mortality, perinatal mortality and/or cerebral palsy were included. Relative risks were calculated from extracted data, and meta-analysis of randomised controlled trials was undertaken.

Findings: Nine randomised controlled trials and 26 non-experimental studies were included. Metaanalysis of pooled data from RCTs in mixed- and high-risk populations found no statistically significant differences in perinatal mortality rates. The majority of non-experimental research was at critical risk of bias and should not be relied on to inform practice. Cardiotocograph monitoring during preterm labour was associated with a higher incidence of cerebral palsy.

Discussion: Research evidence failed to demonstrate perinatal benefits from intrapartum cardiotocograph monitoring for women at risk for poor perinatal outcome.

Conclusion: There is an urgent need for well-designed research to consider whether intrapartum cardiotocograph monitoring provides benefits.
\end{abstract}

(c) 2019 Australian College of Midwives. Published by Elsevier Ltd. All rights reserved.

\section{Statement of significance}

\section{Problem}

The use of intrapartum CTG monitoring is widespread, particularly for women considered to be at risk for poor perinatal outcome. The use of intrapartum CTG monitoring increases the risk of surgical birth.

\section{What is already known}

Intrapartum CTG monitoring does not prevent perinatal death or cerebral palsy in infants born to low risk women.

\section{What this paper adds}

Current research evidence does not demonstrate improvements in perinatal outcome for infants born to women at risk of poor perinatal outcome when intrapartum CTG monitoring is used.

\footnotetext{
* Corresponding author at: Transforming Maternity Care Collaborative, School of Nursing and Midwifery, Logan Campus, Griffith University, University Drive, Meadowbrook, 4131 Qld, Australia.

E-mail addresses: k.small@griffith.edu.au (K.A. Small),

m.sidebotham@griffith.edu.au (M. Sidebotham), j.fenwick@griffith.edu.au

(J. Fenwick), j.gamble@griffith.edu.au (J. Gamble).
} 


\section{Introduction}

Intrapartum cardiotocograph (CTG) monitoring was introduced in the 1970s. ${ }^{1}$ The CTG records and displays the fetal heart rate and uterine tone over time making it possible to examine relationships between heart rate and uterine activity. Fetal heart rate patterns are considered to provide physiological information regarding oxygenation of the fetus. ${ }^{2}$ During labour a reduction in placental blood flow occurs during uterine contractions. ${ }^{3}$ This reduction may place the fetus at risk for low oxygenation. ${ }^{4}$ Hypoxia is presumed to be responsible for a proportion of perinatal deaths and cases of cerebral palsy (CP).,

CTG monitoring was introduced as a screening tool in order to detect fetal hypoxia so that corrective action could be taken. ${ }^{7}$ The goals of intrapartum CTG monitoring include reducing perinatal mortality and CP. CTG monitoring confers no benefits over intermittent auscultation (IA) for women considered to be at low risk for poor perinatal outcome. ${ }^{8}$ Most professional guidelines regarding intrapartum fetal monitoring therefore consider that IA is appropriate for women at low risk. Continuous intrapartum CTG monitoring for women at risk is universally recommended within professional guidelines. ${ }^{9-13}$ Caesarean section rates have increased over the past two decades, ${ }^{14}$ with clear evidence that use of CTG monitoring contributes to increases in the use of caesarean section. ${ }^{15}$ Rates of maternal mortality and significant maternal morbidity appear to be increasing in some high income countries ${ }^{16}$ and are associated with rising caesarean section rates. ${ }^{17,18}$

The Royal Australian and New Zealand College of Obstetricians and Gynaecologists Intrapartum Fetal Surveillance guideline acknowledge that evidence from randomised controlled trials (RCTs) do not demonstrate a perinatal benefit from intrapartum CTG monitoring for infants born to women with risk factors but suggests that non-experimental evidence supports this practice and therefore justifies the guideline's recommendations for CTG use. ${ }^{9}$ No systematic review of non-experimental research regarding intrapartum CTG use in high risk women has previously been undertaken. The Cochrane review of RCTs investigating intrapartum CTG monitoring included subgroup analyses for high and mixed risk populations of women, but this information was not foregrounded within the review making it easy to overlook.

Given that CTG monitoring is associated with surgical risks for women, it is important to revisit the evidence regarding intrapartum CTG monitoring to ensure that current efforts to reduce perinatal hypoxic injury and death are effective and balance this risk. The research question underpinning this systematic literature review and meta-analysis was: does continuous intrapartum CTG monitoring modify the risk for fetal or neonatal mortality, or cerebral palsy, for infants born to women who are considered to be at increased risk of experiencing perinatal mortality or CP? In order to address this question evidence from both RCTs and nonexperimental research was examined.

\section{Methods}

\section{Literature search}

This systematic literature review was registered prospectively with PROSPERO (CRD42018114637). The PubMed, Cumulative Index to Nursing and Allied Health Literature, Cochrane Library, and Web of Science databases were searched in November 2018 and updated in July 2019. The search string used was ("Cardiotocography" OR "Fetal Monitoring" OR "Monitoring, Physiologic") AND ("Labor, Obstetric" OR "Delivery, Obstetric"). The search was limited to English language publications, humans and no date limits were set.

The searches returned 1853 matches, spanning the years 19662019. Titles and abstracts of the papers were assessed against inclusion and exclusion criteria (see Fig. 1). Included in the review were original research papers examining continuous intrapartum CTG monitoring which reported on at least one of the outcomes of interest: perinatal mortality, neonatal mortality, stillbirth, or CP. Reference lists were examined, along with those of the Cochrane review of intrapartum CTG monitoring ${ }^{8}$ and other systematic literature reviews ${ }^{19-22}$ and 40 additional papers were identified.

Full text copies of 74 papers were read and excluded if they reported data later included in a subsequent publication (when this occurred, the most complete data set was included), if the population was women at low risk, or when comparisons were not made between intrapartum CTG monitoring and IA. Many of the early papers referred to the comparison group as having "no monitoring" and it has been assumed that IA was in use for this group of women.

A total of 36 papers were excluded at the full text review. Fifteen provided no outcome data, and two examined populations of women at low risk. Six papers presented data published again later. Eight papers compared restricted CTG use with liberal CTG use. These were excluded as women at risk were likely to have been equally included in both cohorts. One RCT was excluded as intermittent electronic fetal heart monitoring without uterine tone monitoring was used rather than CTG monitoring. Also excluded were two papers reporting outcomes in a population of women exposed to CTG monitoring with no comparison group, and another published only as an abstract and lacking detail. A final unpublished RCT data set referred to in the Cochrane review was unable to be obtained.

\section{Risk of bias assessment}

The 38 included papers were assessed for risk of bias. The Risk of Bias in Nonrandomised Studies of Interventions (ROBINS-I) tool $^{23}$ was used to assess the non-experimental research. None of the papers provided information regarding the use of cointerventions which might have altered outcomes (such as fetal scalp blood sampling). This parameter was therefore disregarded. All the included RCTs had previously been assessed for risk of bias by the authors of the Cochrane review of intrapartum CTG monitoring, ${ }^{8}$ and these results were utilised.

\section{Data extraction}

Included papers were read and data on the total number of births and the number of stillbirths, neonatal deaths and/or perinatal deaths were extracted (when available) and summarised in tabular form. Definitions for stillbirth, neonatal and perinatal mortality were not always expressed, and when they were, these varied. No attempt has been made to correct for this. When information regarding both the intrapartum stillbirth rate and either the antenatal or total stillbirth rate was reported, only the intrapartum rate was extracted. When the neonatal mortality rate was corrected for lethal anomalies, this figure was used in preference to the raw data. When it was not otherwise specified, perinatal mortality was calculated as the sum of stillbirth and neonatal mortality rates.

\section{Data analysis}

Results from non-experimental and RCT research were analysed separately. Study designs and definitions used within the nonexperimental research varied significantly, hence the outcome data were not summarised into a single figure. The majority of the non-experimental data did not report measures of statistical significance. Where sufficient data extracted from the papers enabled this, rates of stillbirth, neonatal mortality, perinatal 


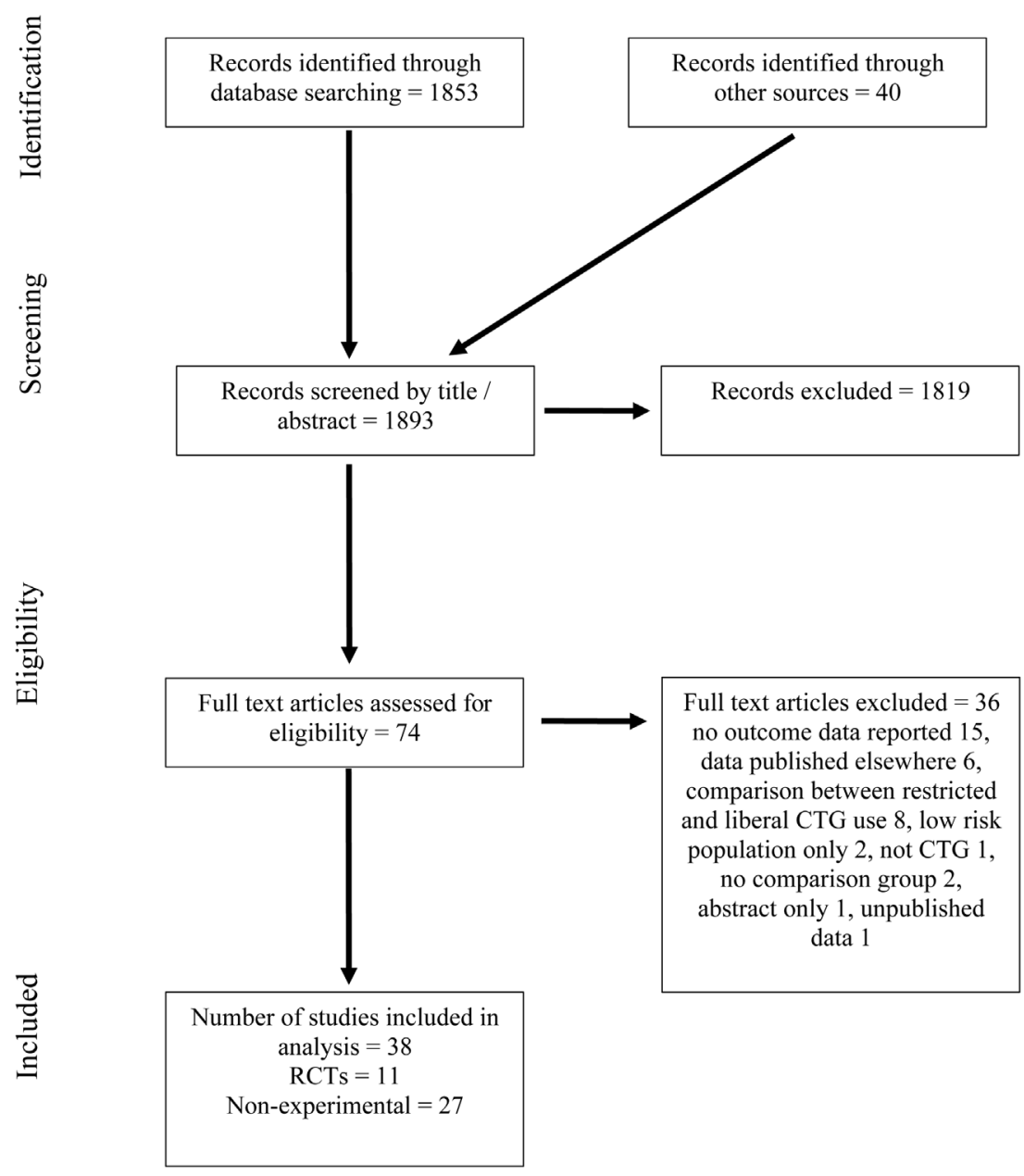

Fig. 1. PRISMA diagram.

mortality and cerebral palsy were calculated per 1000 births. Risk ratios (RR) and 95\% confidence intervals (95\% CI) were also retrospectively calculated from the raw data. When the data was insufficient to perform such calculations, the results presented by the original authors were used.

RCTs were grouped into high- and mixed-risk populations for meta-analysis. RRs and 95\% CIs were calculated for each outcome. Meta-analysis of pooled data used the fixed effects Mantel-Haenszel test, as the $\mathrm{I}^{2}$ test for heterogeneity was low. Review Manager software $(\mathrm{v} 5 \cdot 3 \cdot 5)$ was used to perform all statistical calculations.

\section{Findings}

\section{Non-experimental research}

Twenty-seven non-experimental papers reported data between 1972 and 2018. Data from Fleet et al. ${ }^{24}$ and Hopkins et al. ${ }^{25}$ were merged, as the earlier paper provided data prior to and the latter provided data after CTG monitoring was introduced. Most research $(n=16)$ was undertaken in the United States of America (USA). The remainder was conducted in Canada $(n=3)$, Denmark $(n=2)$, the United Kingdom (UK) $(n=1)$, Africa $(n=1)$, Germany $(n=1)$, Israel $(n=1)$, Norway $(n=1)$, and Switzerland $(n=1)$.

\section{Risk of bias assessment}

The most common potential bias regarded recognising and controlling for confounding variables, which was a critical issue for
22 papers. One paper was assessed as being at serious risk in the category of classification of intervention. ${ }^{26}$ Women in this research were retrospectively assigned to risk categories on the basis of their birth outcome. Only four papers had moderate risk of bias; a level considered compatible with providing sound evidence for practice. ${ }^{27-30}$

\section{Research approaches}

Table 1 describes the approaches used and the findings of the non-experimental research. Most used a times series design, comparing a time period prior to the introduction of intrapartum CTG monitoring with a period following introduction of CTG monitoring, ${ }^{24,25,32-45}$ which always favoured CTG use among women at risk. The remaining studies used cross-sectional design. Three papers compared a population of women at low risk for poor perinatal outcome who were not monitored by CTG, with a population at high risk monitored by CTG during the same time period. ${ }^{46-48}$ Philpott and Stewart's research compared two high risk groups, with nature of the risk factors being different between the two groups. ${ }^{49}$ One team compared a group of women where CTG monitoring was not used in labour with a group where it was used, and generated subsets on the basis of risk assessment. ${ }^{50}$ The findings from the two highest risk subgroups have been merged. In this study, differences in the type of monitoring used arose due to limted numbers of monitors. It is probable that there were significant differences between the study populations that account for differences in outcomes. 
Table 1

Non-experimental research on intrapartum CTG monitoring for women at increased risk for poor perinatal outcome.

\begin{tabular}{|c|c|c|c|c|c|c|c|c|c|c|c|c|c|}
\hline \multirow{2}{*}{$\begin{array}{l}\text { ROBINS-I bias } \\
\text { risk }\end{array}$} & \multirow{2}{*}{$\begin{array}{l}\text { Author, year } \\
\text { Prior to vs after introduction of CT }\end{array}$} & \multirow[t]{2}{*}{ Country } & \multirow[t]{2}{*}{$\begin{array}{l}\text { Study } \\
\text { design }\end{array}$} & \multirow[t]{2}{*}{$\begin{array}{l}\text { Number of } \\
\text { births }\end{array}$} & \multicolumn{3}{|c|}{ Stillbirth rate (per 1000 births) } & \multicolumn{3}{|c|}{ Neonatal mortality rate (per 1000 births) } & \multicolumn{3}{|c|}{$\begin{array}{l}\text { Perinatal mortality rate (per } \\
1000 \text { births) }\end{array}$} \\
\hline & & & & & Prior & After & $\mathrm{RR}(95 \% \mathrm{CI})$ & Prior & After & $\mathrm{RR}(95 \% \mathrm{CI})$ & Prior & After & $\mathrm{RR}(95 \% \mathrm{CI})$ \\
\hline & Hill, $1972^{32}$ & USA & Time series & ND & ND & ND & $\mathrm{NA}$ & ND & ND & NA & 10.0 & 5.0 & $\mathrm{NA}$ \\
\hline & Gabert \& Stenchever, $1973^{33}$ & USA & Time series & 2388 & 11.1 & 17.6 & $\begin{array}{l}1.60(0.79- \\
3.22)\end{array}$ & 19.5 & 7 & $\begin{array}{l}0.36(0.15- \\
0.86) \mathrm{a}\end{array}$ & 30.6 & 24.6 & $\begin{array}{l}0.80(0.47- \\
1.35)\end{array}$ \\
\hline & Koh, et al., $1975^{34}$ & Canada & Time series & 2241 & 3.4 & 7.4 & $\begin{array}{l}2.16(0.65- \\
7.19)\end{array}$ & 4.3 & 4.6 & $\begin{array}{l}1.08(0.31- \\
3.72)\end{array}$ & 7.8 & 12.0 & $\begin{array}{l}1.56(0.66- \\
3.66)\end{array}$ \\
\hline & Shenker et al., $1975^{35}$ & USA & Time series & 11,770 & 6.7 & 7.8 & $\begin{array}{l}1.16(0.68- \\
1.97)\end{array}$ & 7.9 & 5.7 & $\begin{array}{l}0.72(0.43- \\
1.21)\end{array}$ & 14.6 & 13.5 & $\begin{array}{l}0.92(0.64- \\
1.34)\end{array}$ \\
\hline & Hochuli et al., $1976^{36}$ & Switzerland & Time series & ND & $\begin{array}{l}\text { Approx. } \\
1\end{array}$ & $\begin{array}{l}\text { Approx. } \\
1\end{array}$ & $\mathrm{NA}$ & Approx. 5 & Approx. 2 & NA & 9.0 & 5.0 & NA \\
\hline & Lee \& Baggish, $1976^{37}$ & USA & Time series & 7852 & 11.8 & 8.8 & $\begin{array}{l}0.79(0.50- \\
1.24)\end{array}$ & 13.0 & 6.0 & $\begin{array}{l}0.46(0.28- \\
0.75) \mathrm{a}\end{array}$ & 24.1 & 14.7 & $\begin{array}{l}0.61(0.43- \\
0.85)^{\mathrm{a}}\end{array}$ \\
\hline & Papageorgiou et al., $1977^{38}$ & Canada & Time series & 8481 & 13.4 & 6.4 & $\mathrm{NA}$ & 7.6 & 4.5 & $\mathrm{NA}$ & 20.9 & 10.9 & $\mathrm{NA}$ \\
\hline & Hamilton et al., $1978^{39}$ & USA & Time series & 8589 & 2.6 & 0.2 & $\begin{array}{l}0.09(0.01- \\
0.70)^{\mathrm{a}}\end{array}$ & 8.9 & 8.8 & $\begin{array}{l}0.99(0.63- \\
1.55)\end{array}$ & 21.1 & 14.4 & $\begin{array}{l}0.68(0.49- \\
0.94)^{\mathrm{a}}\end{array}$ \\
\hline & Johnstone et al., $1978^{40}$ & UK & Time series & 16,411 & 1.2 & 0.4 & $\begin{array}{l}0.34(0.09- \\
1.22)\end{array}$ & ND & ND & NA & 1.9 & 0.8 & $\begin{array}{l}0.44(0.17- \\
1.11)\end{array}$ \\
\hline & Weinraub et al., $1978^{41}$ & Israel & Time series & 1218 & 4.5 & 0 & $\begin{array}{l}0.18(0.01- \\
3.41)\end{array}$ & 13.4 & 1.8 & $\begin{array}{l}0.14(0.02- \\
1.07)\end{array}$ & 17.8 & 1.8 & $\begin{array}{l}0.10(0.01- \\
0.78)^{a}\end{array}$ \\
\hline & $\begin{array}{l}\text { Fleet et al., 1976; Hopkins, et al., } \\
1979^{24,25 d}\end{array}$ & USA & Time series & 25,673 & 22.5 & 20.1 & $\begin{array}{l}0.89(0.73- \\
1.09)\end{array}$ & 26.5 & 31.4 & $\begin{array}{l}1.19(1.00- \\
1.41) \mathrm{a}\end{array}$ & 49.0 & 51.5 & $\begin{array}{l}1.05(0.92- \\
1.20)\end{array}$ \\
\hline & Shamsi et al., $1979^{42}$ & USA & Time series & 10,853 & 7.3 & 7.6 & $\begin{array}{l}1.04(0.67- \\
1.63)\end{array}$ & 10.0 & 7.7 & $\begin{array}{l}0.77(0.51- \\
1.16)\end{array}$ & 17.3 & 15.3 & $\begin{array}{l}0.88(0.65- \\
1.19)\end{array}$ \\
\hline & Mueller-Heubach et al., $1980^{43}$ & USA & Time series & 14,914 & 2.2 & 0.6 & $\begin{array}{l}0.27(0.10- \\
0.76)^{a}\end{array}$ & 9.8 & 8.2 & $\begin{array}{l}0.84(0.59- \\
1.18)\end{array}$ & 12.0 & 8.8 & $\begin{array}{l}0.73(0.53- \\
1.01)\end{array}$ \\
\hline & Boehm et al., $1981^{44}$ & USA & Time series & 2607 & ND & ND & NA & 22.6 & 5.1 & $\mathrm{NA}$ & ND & ND & NA \\
\hline & Heinrich, $1982^{45}$ & Germany & Time series & 11,355 & ND & ND & NA & ND & ND & NA & 21.8 & 13.9 & NA \\
\hline & \multicolumn{3}{|c|}{ Low risk with IA vs high risk with CTG } & & IA & CTG & $\mathrm{RR}(95 \% \mathrm{CI})$ & IA & CTG & $\mathrm{RR}(95 \% \mathrm{CI})$ & IA & CTG & $\mathrm{RR}(95 \% \mathrm{CI})$ \\
\hline & Tutera \& Newman, $1975^{46}$ & USA & $\begin{array}{l}\text { Cross- } \\
\text { section }\end{array}$ & 6792 & 6.0 & 2.0 & NA & 8.0 & 0 & NA & 14.0 & 2.0 & NA \\
\hline & Stevens et al., $1976^{47}$ & Canada & $\begin{array}{l}\text { Cross- } \\
\text { section }\end{array}$ & 2721 & 2.3 & 0 & $\begin{array}{l}0.19(0.01- \\
3.47)\end{array}$ & 7.0 & 7.9 & $\begin{array}{l}1.12(0.46- \\
2.76)\end{array}$ & 9.4 & 7.9 & $\begin{array}{l}0.84(0.36- \\
1.97)\end{array}$ \\
\hline & Yeh et al., $1982^{48}$ & USA & $\begin{array}{l}\text { Cross- } \\
\text { section }\end{array}$ & 111,955 & 0.7 & 0.2 & $\begin{array}{l}0.32(0.16- \\
0.64)^{\mathrm{a}}\end{array}$ & 4.6 & 3.5 & $\begin{array}{l}0.76(0.63- \\
0.92)^{\mathrm{a}}\end{array}$ & 5.3 & 3.8 & $\begin{array}{l}0.70(0.59- \\
0.84)^{\mathrm{a}}\end{array}$ \\
\hline & \multicolumn{3}{|c|}{ High risk with IA vs high risk with CTG } & & IA & CTG & $\mathrm{RR}(95 \% \mathrm{CI})$ & IA & CTG & $\mathrm{RR}(95 \% \mathrm{CI})$ & IA & CTG & $\mathrm{RR}(95 \% \mathrm{CI})$ \\
\hline & Philpott \& Stewart, $1974^{49}$ & Africa & $\begin{array}{l}\text { Cross- } \\
\text { section }\end{array}$ & 426 & ND & ND & $\mathrm{NA}$ & ND & ND & NA & 19.7 & 16.6 & $\mathrm{NA}$ \\
\hline & Amato, $1977^{50}$ & USA & $\begin{array}{l}\text { Cross- } \\
\text { section }\end{array}$ & 7207 & 4.0 & 0.2 & $\begin{array}{l}0.06(0.01- \\
0.45)^{\mathrm{a}}\end{array}$ & 15.1 & 1.9 & $\begin{array}{l}0.12(0.06- \\
0.26)^{\mathrm{a}}\end{array}$ & 19.1 & 2.1 & $\begin{array}{l}0.11(0.05- \\
0.22)^{\mathrm{a}}\end{array}$ \\
\hline \multirow[t]{2}{*}{ Serious } & \multirow{2}{*}{$\begin{array}{l}\text { IA vs CTG in high risk population } \\
\text { Greenland et al., } 1985^{26}\end{array}$} & & & & IA & CTG & $\mathrm{RR}(95 \% \mathrm{CI})$ & IA & CTG & $\mathrm{RR}(95 \% \mathrm{CI})$ & IA & CTG & $\mathrm{RR}(95 \% \mathrm{CI})$ \\
\hline & & Denmark & $\begin{array}{l}\text { Cross- } \\
\text { section }\end{array}$ & 4096 & ND & ND & NA & 14.0 & 8.0 & $\begin{array}{l}0.58(0.25- \\
1.35)^{\mathrm{b}}\end{array}$ & ND & ND & NA \\
\hline
\end{tabular}

is risk with IA wigh with CT

section

$35)^{\mathrm{b}}$ 


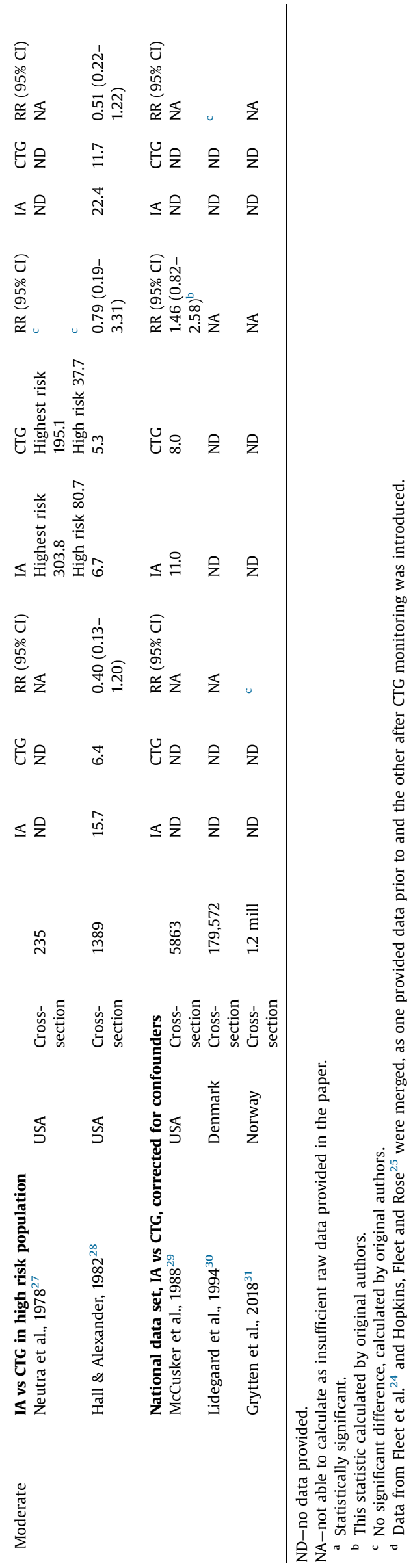

Greenland et al. used analytical techniques to correct for confounding. ${ }^{26}$ Neutra et al. ${ }^{27}$ and Hall and Alexander ${ }^{28}$ used a similar approach, and determined entry into the high-risk group on the basis of predetermined rather than retrospective criteria. Neutra et al. ${ }^{27}$ stratified the population into five risk tiers (highest, high, medium, low and lowest), with the findings from the highest and high categories included in this review. The remaining three papers examined large data sets of routinely collected perinatal data $^{29-31}$ and used analytical techniques to control for confounding. Two calculated the relationship between the incidence of CTG monitoring (which was primarily used for monitoring women at increased risk) and perinatal mortality, ${ }^{29,30}$ with the other calculating the relationship between introduction of CTG monitoring to specific maternity units and subsequent changes in stillbirth incidence. ${ }^{31}$

\section{Outcomes}

$\mathrm{CP}$ was not reported on as an outcome measure in any of the nonexperimental research. The majority of the non-experimental research was hampered by critical risk of bias, particularly in relation to the risk of confounding explaining the findings, which appeared to demonstrate reductions in stillbirth, neonatal mortality and perinatal mortality with the use of intrapartum CTG monitoring. When the five papers with moderate risk of bias were examined, ${ }^{27-31}$ this apparent benefit was no longer present. Three examined neonatal mortality and demonstrated no statistically significant difference in between women with intrapartum CTG monitoring and those who without. ${ }^{27-29}$ Two assessed the stillbirth rate and found no statistically significant difference, ${ }^{28,31}$ while Hall and Alexander ${ }^{28}$ and Lidegaard et al. ${ }^{30}$ measured the overall perinatal mortality rate, again finding no significant difference.

\section{Randomised controlled trials}

Eleven papers reported on nine RCTs with Grant et al. ${ }^{51}$ and Shy et al. ${ }^{52}$ providing cerebral palsy data from the same trials reported by MacDonald et al. ${ }^{53}$ and Luthy et al. ${ }^{54}$ respectively. The RCTs were conducted between 1976 and 2006. Research papers came from Canada $(n=2)$, Ireland $(n=2)$, USA $(n=2)$, Australia $(n=1)$, Denmark $(n=1)$, Greece $(n=1)$, India $(n=1)$, and the UK $(n=1)$.

\section{Risk of bias assessment}

The RCT conducted by Vintzileos et al. ${ }^{55}$ demonstrated high risk for bias (predominantly due to problems with randomisation that resulted in significant differences between the two groups at entry). Renou et al. ${ }^{56}$ demonstrated low risk of bias, as did the two papers reporting on the Dublin trial. ${ }^{51,53}$ The remaining seven papers were assessed as moderate risk due to absence of blinding for outcome assessment. ${ }^{52,54,57-61}$

\section{Research approaches}

The RCTs are summarised in Table 2. Five trials focused on women at high risk. ${ }^{52,54,56-59}$ Both RCTs led by Haverkamp et al. ${ }^{57,58}$ used a risk scoring system to determine the sample, also including women with meconium-stained liquor, oxytocin infusion or abnormal fetal heart patterns detected during auscultation. Renou et al. ${ }^{56}$ recruited women with meconiumstained liquor, medical or obstetrical complications, or with abnormal fetal heart patterns detected during auscultation. Women in labour with a singleton infant between 26 and 32 weeks of gestation were recruited by Luthy et al., ${ }^{54}$ with Shy et al. ${ }^{52}$ reporting on cerebral palsy outcomes for this cohort. The final RCT $^{59}$ enrolled women with one previous lower uterine segment caesarean section.

Four RCTs, published over five papers, included a mix of women at lower and higher risk. ${ }^{51,53,55,60,61}$ These papers did not stratify 
Table 2

RCT research on intrapartum CTG monitoring for women at increased risk for poor perinatal outcome.

\begin{tabular}{|c|c|c|c|c|c|c|c|c|c|c|c|c|c|c|c|}
\hline \multirow[t]{2}{*}{$\begin{array}{l}\text { Risk of } \\
\text { bias }\end{array}$} & \multirow{2}{*}{$\begin{array}{l}\text { Author, year } \\
\text { High risk population }\end{array}$} & \multirow[t]{2}{*}{ Country } & \multirow[t]{2}{*}{$\begin{array}{l}\text { No of } \\
\text { births }\end{array}$} & \multicolumn{3}{|c|}{$\begin{array}{l}\text { Stillbirth rate (per } \\
1000 \text { births) }\end{array}$} & \multicolumn{3}{|c|}{$\begin{array}{l}\text { Neonatal mortality rate } \\
\text { (per } 1000 \text { births) }\end{array}$} & \multicolumn{3}{|c|}{$\begin{array}{l}\text { Perinatal mortality rate } \\
\text { (per } 1000 \text { births) }\end{array}$} & \multicolumn{3}{|c|}{$\begin{array}{l}\text { Cerebral palsy rate (per } \\
1000 \text { births) }\end{array}$} \\
\hline & & & & IA & CTG & $\mathrm{RR}(95 \% \mathrm{CI})$ & IA & CTG & $\mathrm{RR}(95 \% \mathrm{CI})$ & IA & CTG & RR (95\%CI) & IA & CTG & $\mathrm{RR}(95 \% \mathrm{CI})$ \\
\hline Mod & Haverkamp et al., $1976^{57}$ & USA & 483 & 0 & 0 & NA & 0 & 4.1 & $\begin{array}{l}2.99(0.12- \\
72.98)\end{array}$ & 0 & 4.1 & $\begin{array}{l}2.99(0.12- \\
72.98)\end{array}$ & ND & ND & NA \\
\hline \multirow{5}{*}{ Low } & Haverkamp et al., $1979^{58}$ & USA & 695 & 0 & 0 & NA & 0 & 6.5 & $\begin{array}{l}3.52(0.18- \\
67.77)\end{array}$ & 0 & 6.5 & $\begin{array}{l}3.52(0.18- \\
67.77)\end{array}$ & ND & ND & NA \\
\hline & $\begin{array}{l}\text { Luthy et al., 1987; Shy et al., } \\
1990^{52,54}\end{array}$ & Canada & 239 & 8.3 & 8.4 & $\begin{array}{l}1.01(0.06- \\
15.94)\end{array}$ & 108.3 & 109.2 & $\begin{array}{l}1.01(0.49- \\
2.08)\end{array}$ & 116.7 & 117.6 & $\begin{array}{l}1.01(0.50- \\
2.02)\end{array}$ & 76.9 & 195.1 & $\begin{array}{l}2.91(1.13- \\
7.48)^{\mathrm{a}}\end{array}$ \\
\hline & Madaan \& Trivedi, $2006^{59}$ & India & 100 & 0 & 0 & NA & 0 & 0 & NA & 0 & 0 & $\mathrm{NA}$ & ND & ND & NA \\
\hline & Renou et al., $1976^{56}$ & Australia & 440 & 4.5 & 0 & $\begin{array}{l}0.34(0.01- \\
8.29)\end{array}$ & 0 & 4.6 & $\begin{array}{l}3.05(0.13- \\
74.58)\end{array}$ & 4.5 & 4.6 & $\begin{array}{l}1.02(0.06- \\
16.18)\end{array}$ & ND & ND & NA \\
\hline & Total & & 1957 & 2.3 & 0.9 & $\begin{array}{l}0.61(0.08- \\
4.58)\end{array}$ & 15.0 & 16.5 & $\begin{array}{l}1.26(0.65- \\
2.44)\end{array}$ & 17.3 & 17.4 & $\begin{array}{l}1.17(0.62- \\
2.22)\end{array}$ & 76.9 & 195.1 & $\begin{array}{l}2.91(1.13- \\
7.48)^{\mathrm{a}}\end{array}$ \\
\hline & Mixed risk population & & & & & & & & & & & & & & \\
\hline High & Vintzileos et al., $1993^{55}$ & Greece & 1428 & 2.9 & 0 & $\begin{array}{l}0.18(0.01- \\
3.80)\end{array}$ & 10.3 & 2.7 & $\begin{array}{l}0.26(0.05- \\
1.25)\end{array}$ & 13.2 & 2.7 & $\begin{array}{l}0.23(0.05- \\
1.07)\end{array}$ & ND & ND & NA \\
\hline \multirow[t]{2}{*}{ Mod } & Kelso et al., $1978^{60}$ & UK & 504 & 0 & 0 & NA & 4.0 & 0 & $\begin{array}{l}0.33(0.01- \\
8.08)\end{array}$ & 4.0 & 0 & $\begin{array}{l}0.33(0.01- \\
8.08)\end{array}$ & ND & ND & NA \\
\hline & Badawi and Keogh, $1986^{65}$ & Denmark & 978 & 2.0 & 0 & $\begin{array}{l}0.34(0.01- \\
8.30)\end{array}$ & 0 & 0 & NA & 2.0 & 0 & $\begin{array}{l}0.34(0.01- \\
8.30)\end{array}$ & ND & ND & NA \\
\hline \multirow[t]{2}{*}{ Low } & $\begin{array}{l}\text { Grant et al., 1989; MacDonald } \\
\text { et al, } 1985^{51,53}\end{array}$ & Ireland & 13,084 & 0.3 & 0.5 & $\begin{array}{l}1.51(0.25- \\
9.01)\end{array}$ & 1.8 & 1.7 & $\begin{array}{l}0.92(0.41- \\
2.08)\end{array}$ & 2.1 & 2.1 & $\begin{array}{l}1.00(0.48- \\
2.10)\end{array}$ & 1.5 & 1.8 & $\begin{array}{l}1.20 \\
(0.52- \\
2.79)\end{array}$ \\
\hline & Total & & 15,994 & 0.6 & 0.4 & $\begin{array}{l}0.65(0.19- \\
2.30)\end{array}$ & 2.5 & 1.6 & $\begin{array}{l}0.65(0.33- \\
1.28)\end{array}$ & 3.1 & 2.0 & $\begin{array}{l}0.67(0.36- \\
1.23)\end{array}$ & 1.5 & 1.8 & $\begin{array}{l}1.20 \\
(0.52- \\
2.79)\end{array}$ \\
\hline
\end{tabular}

ND - no data provided.

NA - not able to calculate as insufficient raw data provided in the paper.

a statistically significant.

women according to risk and given that the risk factors reported were not mutually exclusive it is difficult to ascertain the number of women within each risk category. The proportions of women with risk factors described are summarised in Table 3 and suggest that the majority of women in these trials would be considered at high risk.

\section{Outcomes}

High risk. No RCT in a population of women at high risk demonstrated statistically significant differences in stillbirth, neonatal mortality, or perinatal mortality rates according to monitoring method (Table 2). Meta-analysis of the pooled data $(\mathrm{n}=1957)$ also showed no statistically significant differences in stillbirth rate (2.3 IA vs 0.9 CTG, RR $0.61,95 \%$ CI 0.08-4.58), neonatal mortality rate (15.0 IA vs 16.5 CTG, RR 1.26 , 95\% CI $0.65-$ 2.44 ), or perinatal mortality rate (17.3 IA vs 17.4 CTG, RR $1.17,95 \% \mathrm{CI}$ $0.62-2.22$ ). There was however a statistically significant increase in the incidence of CP among infants monitored by intrapartum CTG rather than IA (76.9 IA vs 195.1 CTG, RR 2.91, 95\% CI 1.13-7.48). This finding emerged from a population of women at risk as a consequence of preterm birth. ${ }^{52}$
Mixed risk. Among the RCTs conducted in populations of women at mixed risk, none demonstrated statistically significant differences in stillbirth, neonatal mortality, or perinatal mortality rates. Meta-analysis of the pooled data from all RCTs regarding women of mixed risk $(n=15,994)$ found no differences in the rate of stillbirth (0.6 IA vs 0.4 CTG, RR $0.65,95 \%$ CI 0.19-2.30), neonatal mortality (2.5 IA vs 1.6 CTG, RR $0.65,95 \%$ CI $0.33-1.28$ ) or perinatal mortality (3.1 IA vs 2.0 CTG, RR $0.67,95 \%$ CI $0.36-1.23$ ). The only trial to assess $\mathrm{CP}^{51}$ found no difference in this outcome (1.5 IA vs 1.8 CTG, RR 1.20, 95\% CI 0.52-2.79).

\section{Discussion}

Only non-experimental studies at critical risk of bias showed reductions in perinatal mortality related to intrapartum CTG monitoring. During the 1970s and 1980s significant advances occurred in neonatal care. ${ }^{62,63}$ Contraception and pregnancy termination became increasingly available, and there was a reduction in preterm birth which is known to be a strong determinant of perinatal mortality. ${ }^{64}$ These changes occurred contemporaneously with the introduction and expansion of CTG use and may well explain the apparent benefit from

Table 3

RCTs in mixed risk populations: reported proportion of women with risk factors for poor perinatal outcome.

\begin{tabular}{|c|c|}
\hline Author, year & Risk factors described \\
\hline Vintzileos et al., $1993^{55}$ & $\begin{array}{l}\text { Antenatal history } 13 \% \text {, oxytocin infusion } 57 \% \text {, meconium stained liquor } 14 \% \text {, preterm labour } 7 \% \text {, post-term labour } 3 \% \text {, breech } \\
\text { presentation } 2 \% \text {. }\end{array}$ \\
\hline Kelso et al., $1978^{60}$ & $\begin{array}{l}\text { Oxytocin infusion } 50 \% \text {, epidural } 36 \% \text {. Meconium stained liquor was not an exclusion criterion, but the proportion of women with this } \\
\text { was not documented. }\end{array}$ \\
\hline Neldam et al., $1986^{61}$ & $\begin{array}{l}43 \% \text { described as high risk. This classification was not inclusive of oxytocin infusion in } 40 \% \text {, epidural in } 9 \% \text {. Whether meconium } \\
\text { stained liquor was an exclusion criterion was not described and the proportion of women with this was not documented. }\end{array}$ \\
\hline $\begin{array}{l}\text { Grant et al., 1989; Macdonald et al., } \\
\qquad 1985^{51,53}\end{array}$ & $\begin{array}{l}23 \% \text { were described as high risk. This classification was not inclusive of oxytocin infusion in } 23 \% \text {, preterm labour } 3 \% \text {, post-term labour } \\
13 \% \text {, epidural } 3 \% \text {. Moderate to heavy meconium staining of liquor was an exclusion criterion, with the number of women with light } \\
\text { meconium staining not described. }\end{array}$ \\
\hline
\end{tabular}


CTG monitoring seen in this research. Non-experimental research addressing such confounders showed no statistically significant differences in mortality rates.

These findings aligned with evidence from RCTs, which also demonstrated no difference in mortality rates between the two intrapartum monitoring options. The impact on $\mathrm{CP}$ has been underinvestigated, having been addressed by only two RCTs. The first (in a mixed risk cohort) found no difference in the rate of $\mathrm{CP}$ with intrapartum CTG monitoring. ${ }^{51}$ There has been increasing recognition that intrapartum hypoxia does not play a major role in the development of $\mathrm{CP},{ }^{65}$ so this finding is perhaps unsurprising. What was surprising (particularly given that no other research has sought to replicate the findings in the three decades since), was the $291 \%$ increase in CP when women with preterm labour were randomised to intrapartum CTG monitoring. ${ }^{52}$ It is not clear why this occurred, with no differences in Apgar scores, cord blood gas $\mathrm{pH}$ or caesarean rates noted between the two approaches to monitoring. ${ }^{54}$ Earlier gestational age increases the incidence and severity of $\mathrm{CP},{ }^{17}$ so even a small increase in relative risk is likely to have a significant impact on the incidence of $\mathrm{CP}$ at a whole of population level.

Since its introduction assumptions have been made that intrapartum CTG monitoring would provide maternity professionals with "an essential diagnostic technique in obstetrical practice which improves such fetal outcomes as perinatal mortality, morbidity and neonatal status". ${ }^{66}$ This assumption cannot be supported by research undertaken to date.

\section{Strengths and limitations}

A Cochrane review has considered only the RCT evidence regarding intrapartum CTG monitoring. ${ }^{8}$ This literature review reiterates their analysis of the RCT evidence and also incorporates critique and analysis of the large body of non-experimental evidence. The search was limited to the English language, so it remains possible that publications in other languages might have contributed different findings. Given the age of the research, obtaining additional material from authors was considered unfeasible. As a consequence, unpublished data that might have added to the findings is absent. Significant changes in the provision of maternity care and the social context in which care is provided have occurred since the majority of the research was undertaken, which impact on the generalisability of the findings.

\section{Conclusion}

Evidence from quality non-experimental research and RCTs shows no difference in the rates of stillbirth, neonatal mortality or perinatal mortality between the use of IA or CTG monitoring during labour in populations that include or consist of women considered to be at increased risk for poor perinatal outcome. Intrapartum fetal surveillance guidelines which recommend CTG monitoring for women considered to be at risk are not consistent with the evidence base. Clinicians and professional bodies have an obligation to provide maternity consumers with recommendations that are underpinned by sound evidence.

\section{Recommendations}

It is important that pregnant women receive accurate information regarding the lack of evidence of benefit for intrapartum CTG monitoring when risk factors for poor perinatal outcome are present. Women experiencing preterm labour should be advised that the use of intrapartum CTG monitoring might be associated with an increased risk of $\mathrm{CP}$, with no other apparent perinatal benefits.
Assumptions that intrapartum CTG monitoring improves perinatal outcomes potentially hamper research efforts to identify alternate interventions that might be effective in preventing perinatal loss or CP. There is urgent need to verify whether intrapartum CTG monitoring during preterm labour impacts on $\mathrm{CP}$ rates. High-quality research is urgently required to identify which women, if any, obtain a perinatal benefit from intrapartum CTG monitoring.

\section{Ethics statement}

None declared.

\section{Funding}

None declared.

\section{Conflict of interest}

None declared.

\section{CRediT authorship contribution statement}

Kirsten A. Small: Conceptualization, Data curation, Formal analysis, Methodology, Writing - original draft, Writing - review \& editing. Mary Sidebotham: Supervision, Validation, Writing review \& editing. Jennifer Fenwick: Supervision, Writing - review \& editing. Jenny Gamble: Supervision, Validation, Writing - review \& editing.

\section{Acknowledgements}

The authors would like to acknowledge the assistance of Ms Bonnie Dixon, Health Librarian, Griffith University who assisted in structuring the search terms, and Professor Rob Ware, Menzies Health Institute, for statistical advice.

\section{References}

1. Stout MJ, Cahill AG. Electronic fetal monitoring: past, present, and future. Clin Perinatol 2011:38(1):127-42.

2. Ugwumadu A. Understanding cardiotocographic patterns associated with intrapartum fetal hypoxia and neurologic injury. Best Pract Res Clin Obstet Gynaecol 2013;27(4):509-36.

3. Yli BM, Kjellmer I. Pathophysiology of foetal oxygenation and cell damage during labour. Best Pract Res Clin Obstet Gynaecol 2015;30:9-21.

4. Schneider H. Oxygenation of the placental-fetal unit in humans. Respir Physiol Neurobiol 2011;178(1):51-8.

5. Reinebrant HE, Leisher SH, Coory M, Henry S, Wojcieszek AM, Gardener G, et al. Making stillbirths visible: a systematic review of globally reported causes of stillbirth. Br J Obstet Gynaecol 2018;125(2):212-24.

6. MacLennan AH, Thompson SC, Gecz J. Cerebral palsy: causes, pathways, and the role of genetic variants. Am J Obstet Gynecol 2015;213(6):779-88.

7. Kennedy RG. Electronic fetal heart rate monitoring: retrospective reflections on a twentieth-century technology. I R Soc Med 1998;91(5):244-50.

8. Alfirevic Z, Devane D, Gyte GML, Cuthbert A. Continuous cardiotocography (CTG) as a form of electronic fetal monitoring (EFM) for fetal assessment during labour. Cochrane Database Syst Rev 2017;2: CD006066.

9. Royal Australian and New Zealand College of Obstetrics and Gynaecology. Intrapartum fetal surveillance. Cited 15 February 2019. Available from:. 3rd ed. Melbourne (Australia): RANZCOG; 2014https://www.ranzcog.edu.au/statements-guidelines/.

10. Ayres-de-Campos D, Spong CY, Chandraharan E, Panel for the FIGO Intrapartum Fetal Monitoring Expert Consensus Panel. FIGO consensus guidelines on intrapartum fetal monitoring: cardiotocography. Int J Gynaecol Obstet 2015;131(1):13-24.

11. National Collaborating Centre for Women's and Children's Health (UK). Intrapartum care: care of healthy women and their babies during childbirth. London: National Institute for Health and Care Excellence (UK); 2014.

12. Liston RM, Sawchuck D, Young D. No. 197b-fetal health surveillance: intrapartum consensus guideline. J Obstet Gynaecol Can 2018;40(4):e298-322.

13. American College of Obstetricians and Gynecologists. ACOG practice bulletin no. 106: intrapartum fetal heart rate monitoring: nomenclature, interpretation, and general management principles. Obstet Gynecol Surv 2009;114 (1):192-202 
14. Betran AP, Ye J, Moller A-B, Zhang J, Gülmezoglu AM, Torloni MR. The increasing trend in caesarean section rates: global, regional and national estimates: 1990-2014. PLoS One 2016;11(2)e0148343.

15. Paterno MT, McElroy K, Regan M. Electronic fetal monitoring and cesarean birth: a scoping review. Birth 2016;43(4):277-84.

16. Mhyre JM. Maternal mortality. Curr Opin Anaesthesiol 2012;25(3):277-85.

17. Kallianidis AF, Schutte JM, van Roosmalen J, van den Akker T, Maternal Mortality and Severe Morbidity Audit Committee of the Netherlands Society of Obstetrics and Gynecology. Maternal mortality after cesarean section in the Netherlands. Eur J Obstet Gynecol Reprod Biol 2018;229:148-52.

18. Esteves-Pereira AP, Deneux-Tharaux C, Nakamura-Pereira M, Saucedo M, Bouvier-Colle M-H, Leal MDC. Caesarean delivery and postpartum maternal mortality: a population-based case control study in Brazil. PLoS One 2016;11(4) e0153396.

19. Banta HD, Thacker SB. Assessing the costs and benefits of electronic fetal monitoring. Obstet Gynecol Surv 1979;34(8):627-42.

20. Zuspan FP, Quilligan EJ, Iams JD, van Geijn HP. Predictors of intrapartum fetal distress: the role of electronic fetal monitoring. Report of the National Institute of Child Health and Human Development Consensus Development Task Force. Am J Obstet Gynecol 1979;135(3):287-91.

21. Vintzileos AM, Nochimson DJ, Guzman ER, Knuppel RA, Lake M, Schifrin BS. Intrapartum electronic fetal heart rate monitoring versus intermittent auscultation: a meta-analysis. Obstet Gynecol Surv 1995;85(1):149-55.

22. Thacker SB, Stroup DF, Peterson HB. Efficacy and safety of intrapartum electronic fetal monitoring: an update. Obstet Gynecol Surv 1995;86(4 Pt 1):613-20.

23. Sterne JAC, Hernán MA, Reeves BC, Savović J, Berkman ND, Viswanathan M, et al. ROBINS-I: a tool for assessing risk of bias in non-randomized studies of interventions. BMJ 2016;355:i4919.

24. Fleet CM, Hopkins EL, Chrisolm D, Rose GJ, Bepko F, George J, et al. Fetal monitoring in labor. J Natl Med Assoc 1976;68(3):195-7.

25. Hopkins EL, Fleet CM, Rose GJ. Effects of maternal-fetal monitoring on pregnancy outcome in a high risk pregnant population. J Natl Med Assoc 1979;71(9):869-70.

26. Greenland S, Olsen J, Rachootin P, Pedersen GT. Effects of electronic fetal monitoring on rates of early neonatal death, low Apgar score, and cesarean section. Acta Obstet Gynecol Scand 1985;64(1):75-80.

27. Neutra RR, Fienberg SE, Greenland S, Friedman EA. Effect of fetal monitoring on neonatal death rates. $N$ Engl J Med 1978;299(7):324-6.

28. Hall ML, Alexander $\mathrm{CH}$. Fetal monitoring in a community hospital: analysis of health maintenance organization, fee-for-service, and clinic populations. Am J Obstet Gynecol 1982;143(3):277-85.

29. McCusker J, Harris DR, Hosmer DW. Association of electronic fetal monitoring during labor with cesarean section rate and with neonatal morbidity and mortality. Am J Public Health 1988;78(9):1170-4.

30. Lidegaard Ø, Jensen LM, Weber T. Technology use, cesarean section rates, and perinatal mortality at Danish maternity wards. Acta Obstet Gynecol Scand 1994;73(3):240-5.

31. Grytten J, Skau I, Sørenson R, Eskild A. Does the use of diagnostic technology reduce fetal mortality? Health Serv Res 2018;53(6):4437-59.

32. Hill DL. Fetal monitoring. A retrospective evaluation. Minn Med 1972;55 (5):479-81.

33. Gabert HA, Stenchever MA. Continuous electronic monitoring of fetal heart rate during labor. Am J Obstet Gynecol 1973;115(7):919-23.

34. Koh KS, Greves D, Yung S, Peddle LJ. Experience with fetal monitoring in a university teaching hospital. CMAJ 1975;112(4) 455-6-459-60.

35. Shenker L, Post RC, Seiler JS. Routine electronic monitoring of fetal heart rate and uterine activity during labor. Obstet Gynecol Surv 1975;46(2):185-9.

36. Hochuli E, Eberhard J, Dubler O. The effect of modern intensive monitoring in obstetrics on infant mortality and the incidence of hypoxia and acidosis. $J$ Perinat Med 1976;4(2):78-84.

37. Lee WK, Baggish MS. The effect of unselected intrapartum fetal monitoring. Obstet Gynecol Surv 1976;47(5):516-20.

38. Papageorgiou AN, Masson M, Shatz R, Gelfand MM. Specialized perinatal care: impact on perinatal mortality. CMAJ 1977;116(5):506-7.

39. Hamilton LA, Gottschalk W, Vidyasagar D, Horn C, Wynn RM. Effects of monitoring high-risk pregnancies and intrapartum FHR monitoring on perinates. Int J Gynaecol Obstet 1978;15(6):483-90.

40. Johnstone FD, Campbell DM, Hughes GJ. Has continuous intrapartum monitoring made any impact on fetal outcome? Lancet 1978;1(8077):1298300 .
41. Weinraub Z, Caspi E, Brook I, Rahmani P, Bukovsky I, Schreyer P. Perinatal outcome in monitored and unmonitored high-risk deliveries. Isr J Med Sci 1978; 14(2):249-55.

42. Shamsi HH, Petrie RH, Steer CM. Changing obstetric practices and amelioration of perinatal outcome in a university hospital. Am J Obstet Gynecol 1979;133 (8):855-8.

43. Mueller-Heubach E, MacDonald HM, Joret D, Portman MA, Edelstone DI, Caritis SN. Effects of electronic fetal heart rate monitoring on perinatal outcome and obstetric practices. Am J Obstet Gynecol 1980;137(7):758-63.

44. Boehm FH, Davidson KK, Barrett JM. The effect of electronic fetal monitoring on the incidence of cesarean section. Am J Obstet Gynecol 1981;140(3):295-8.

45. Heinrich J. Elective fetal monitoring and obstetrical operative frequency. Eur J Obstet Gynecol Reprod Biol 1982;14(3):143-52.

46. Tutera G, Newman RL. Fetal monitoring: its effect on the perinatal mortality and cesarean section rates and its complications. Am J Obstet Gynecol 1975;122 (6):750-4.

47. Stevens DL, Parker EK, Peddle LJ. Intrapartum fetal monitoring: one year's experience at a Canadian teaching hospital. J Obstet Gynecol Neonatal Nurs 1976;5(2):39-42.

48. Yeh S-Y, Diaz F, Paul RH. Ten-year experience of intrapartum fetal monitoring in Los Angeles County/University of Southern California Medical Center. Am J Obstet Gynecol 1982;143(5):496-500.

49. Philpott RH, Stewart KS. Intensive care of the high-risk fetus in Africa. Clin Obstet Gynaecol 1974;1(1):241-62.

50. Amato JC. Fetal monitoring in a community hospital. A statistical analysis. Obstet Gynecol Surv 1977;50(3):269-74.

51. Grant A, Joy M-T, O’Brien N, Hennessy E, MacDonald D. Cerebral palsy among children born during the Dublin trial randomised trial of intrapartum monitoring. Lancet 1989;334(8674):1233-6.

52. Shy KK, Luthy DA, Bennett FC, Whitfield M, Larson EB, van Belle G, et al. Effects of electronic fetal-heart-rate monitoring, as compared with periodic auscultation, on the neurologic development of premature infants. $N$ Engl Med 1990;322(9):588-93.

53. MacDonald D, Grant A, Sheridan-Pereira M, Boylan PC, Chalmers I. The Dublin randomized controlled trial of intrapartum fetal heart rate monitoring. Am J Obstet Gynecol 1985;152(5):524-39.

54. Luthy DA, Shy KK, van Belle G, Larson EB, Hughes JP, Benedetti T, et al. A randomized trial of electronic fetal monitoring in preterm labor. Obstet Gynecol Surv 1987;69(5):687-95.

55. Vintzileos AM, Antsaklis A, Varvarigos I, Papas C, Sofatzis I, Montgomery JT. A randomized trial of intrapartum electronic fetal heart rate monitoring versus intermittent auscultation. Obstet Gynecol Surv 1993;81(6):899-907.

56. Renou P, Chang A, Anderson I, Wood C. Controlled trial of fetal intensive care. Am J Obstet Gynecol 1976;126(4):470-6.

57. Haverkamp AD, Thompson HE, McFee JG, Cetrulo C. The evaluation of continuous fetal heart rate monitoring in high-risk pregnancy. Am J Obstet Gynecol 1976;125(3):310-20.

58. Haverkamp AD, Orleans M, Langendoerfer S, McFee JG, Murphy J, Thompson HE. A controlled trial of the differential effects of intrapartum fetal monitoring. Am J Obstet Gynecol 1979;134(4):399-412.

59. Madaan $M$, Trivedi SS. Intrapartum electronic fetal monitoring vs. intermittent auscultation in postcesarean pregnancies. Int J Gynecol Obstet 2006:94(2):123-5.

60. Kelso IM, Parsons RJ, Lawrence GF, Arora SS, Edmonds DK, Cooke ID. An assessment of continuous fetal heart rate monitoring in labor. A randomized trial. Am J Obstet Gynecol 1978;131(5):526-32.

61. Neldam S, Osler M, Hansen PK, Nim J, Smith SF, Hertel J. Intrapartum fetal heart rate monitoring in a combined low- and high-risk population: a controlled clinical trial. Eur J Obstet Gynecol Reprod Biol 1986;23(1-2):1-11.

62. Lussky RC, Cifuentes RF, Siddappa AM. A history of neonatal medicine-past accomplishments, lessons learned, and future challenges. Part 1-the first century. J Pediatr Pharmacol Ther 2005;10(2):76-89.

63. Kleinman JC, Kovar MG, Feldman JJ, Young CA. A comparison of 1960 and 19731974 early neonatal mortality in selected states. Am J Epidemiol 1978;108 (6):454-69.

64. Pakter J, Nelson F. Factors in the unprecedented decline in infant mortality in New York City. Bull N Y Acad Med 1974;50(7):839-68.

65. Badawi N, Keogh JM. Causal pathways in cerebral palsy. J Paediatr Child Health 2012;49(1):5-8.

66. Applegate J, Haverkamp AD, Orleans M, Taylor C. Electronic fetal monitoring: implications for obstetrical nursing. Nurs Res 1979;28(6):369-71. 